\title{
Should universities promote employability?
}

\author{
Tristan McCowan \\ (UCL Institute of Education, London) \\ Published in Theory and Research in Education (2015), vol. 13 no. 3, pp. 267-285
}

\begin{abstract}
Employability is becoming increasingly central to the mission and functioning of universities, spurred on by national and supranational agencies, and the demands of marketisation. This article provides a response to the normative dimensions of the question, progressing through four stages: first, there is a brief consideration of the meaning and manifestations of employability, and the historical conditions underpinning its emergence; second, the question is addressed of whether employability is a desirable societal and individual aim per se; third, there is a discussion of the fundamental purpose of the university, drawing on the well-known accounts of Newman and Collini, before - fourth - addressing the principal question of whether and in what way employability might fit within that purpose. It is argued that employability is a valid aim of universities only in so far as it is consistent with the central purpose of the institution to foster human understanding through open-ended enquiry. Further questions are discussed, namely whether other social institutions are better equipped to promote employability, possible costs for the university, the ethical dimension, and differences between public and private institutions.
\end{abstract}

\section{Introduction}

The University of Oxford has recently been placed first in the Global Employability Ranking ${ }^{1}$ an accolade that may or may not serve as a consolation for its rather less distinguished showing of $10^{\text {th }}$ on the Shanghai World Universities list. While elite universities may be less dependent on such metrics (the value of their degrees being 'self-evident'), for the 'new kids on the block', employability credentials have become central to success and survival. Institutions such as Robert Gordon University in Aberdeen, whose banner announces it as "Best UK university for employment" now market themselves to their prospective customers primarily on the basis of the ease with which their graduates will subsequently enter the job market. Prospective students can also do their homework on the average graduate starting salaries of universities - the UK ranking currently topped by the London School of Economics.

\footnotetext{
${ }^{1}$ The ranking is conducted by Emerging Associates and Trendence, on the basis of a survey of employers in 20 countries gauging their views on the reputation of universities.
} 
Universities, and higher education systems, are strongly tied into the logic and functioning of the changing contemporary political economy. The connection expresses itself through the practice of higher education (its management, admissions systems, teaching and learning etc) as well as understandings of its aims and purpose. One of the most prominent aspects of the changing conceptualisation of the contemporary university is its role in promoting employability. For students, undertaking a higher education degree is framed -- largely, if not exclusively -- in terms of becoming more employable. For universities, fulfilling this employability enhancing role is framed as an obligation to society or nation, and (particularly in cash-strapped times) a justification for considerable public expense.

Employability has been forcefully promoted by national governments, initially in Anglophone countries - in the UK the notion received firm endorsement in the 1997 Dearing report - but increasingly in other parts of the world (BIS 2011; British Council 2013; CHEC 2013; UNESCO 2012; Novoa 2007). These efforts have been spurred on by the support of supranational agencies and networks such as the Organisation for Economic Cooperation and Development (OECD 2008a; 2008b), the World Bank (2010) and the European Higher Education Area (Bologna Declaration 1999). Concrete expressions of this commitment at the institutional level have emerged in the form of enhanced careers services, integration of skills development within degree courses, introduction of standalone skills development courses, increased opportunities for work placement, and increasing involvement of employers in curricular design and delivery. These movements have occurred in the context of a changing labour market in which -- with the possible exception of well-established professions such as medicine and engineering -- generic skills have become as important to graduate recruiters as subject-specific knowledge (Harvey 2000). As stated in the Dearing Report (1997):

To survive in the labour market of the future, workers will need new sets of skills, to work across conventional boundaries and see connections between processes, functions and disciplines and, in particular, to manage the learning which will support their careers.

In an empirical sense, this trend is hard to deny (although there is debate over the extent to which it constitutes a fundamental change in the purpose and function of the university). But the normative question remains. Is this trend justified or desirable? Should in fact universities have creating employable graduates as their primary aim, or even a subsidiary aim? As with many questions in the contemporary world, the normative dimension is buried by the apparent inevitability of circumstances. The underlying questions of 'should' are quickly dismissed in the urgency of catching up with the world outside, and indeed, of ensuring the very survival of the institution.

The constant assertions of inevitability may, or may not, be a deliberate attempt to quell resistance and alternatives. Either way, institutions are faced with drifting or being swept away by a current, with little thought for purposeful travel -- other than rowing in whichever direction the current is taking them. Exploring the normative dimensions of this question is worthwhile - even if a definitive 'answer' may not be possible (or desirable), or if consensus will not be reached. The anatomy of the arguments for and implications of the employability agenda must be understood clearly, whether we decide to reject it on grounds firmer than ingrained conservatism, or to embrace it without niggling guilt. In developing a conceptual 
discussion of the issue, this article does not deny the importance of context -- in the genesis of demands for employability, in the way it may manifest itself in institutions and in the kinds of response that might be deemed appropriate -- but considers nevertheless that there is worth in engagement with the political and epistemological principles underpinning those more specific expressions of the trends.

This article, therefore, presents a response to the question of whether universities should promote employability in their students. While not presuming to put forward a political and epistemological position that would be acceptable to all, it presents a map of the conceptual terrain on which the debates are located, and suggests some theoretical tools to aid analysis of the place of employability within the functioning of the institution. In doing so, it engages with the ideas of two prominent commentators on the idea of the university -- Cardinal Newman in the 19th century, and in contemporary times, Stefan Collini -- whose ideas shed light on the role of the institution and its connection to society.

But what does 'should' mean in "Should universities promote employability"? Contained within this question are conceptual understandings and judgements of value about both employability and universities. The first question to be addressed is whether employability should be promoted at all (whether in universities or anywhere else). This question involves determining the origins and implications of employability in relation to the organisation of society, and the fundamental moral and political principles of the good life, and of a just and prosperous society. This article cannot, of course, adequately cover all of these questions for example, the relative merits of capitalist as opposed to other forms of social and economic organisation - but the issues will be touched on briefly.

The second question is whether universities specifically should be promoting employability. Included in this question is an empirical issue of whether universities in fact can promote employability, and of whether other social institutions might be better equipped to serve this purpose. But beyond the empirical aspect, lies the matter of the nature of the university itself, whether employability is in keeping with its fundamental purpose, and the effect that its prioritisation might have on the other functions of the institution.

This article will not make a firm distinction between universities and other higher education institutions, though acknowledging the significant diversification of the sector in recent years. An increasing number of post-secondary institutions are included under the umbrella of 'higher education', some with a mission and mode of functioning clearly distinct from traditional universities. For the purposes of this account, it will be assumed that - whether or not they are research intensive - all higher education institutions aim to foster in students what Winch (2006) terms 'technological' as opposed to 'technical' knowledge: that is, in addition to "putting in effect a body of theoretical knowledge in a particular context for a particular purpose" (a valid aim for many vocational institutions), students potentially become "innovator[s] in respect of the knowledge which underlies the development of new technique" . In addition, while the processes of commercialisation affect all aspects of universities, this article will focus primarily on their teaching function, viewing employability as a question of student development through university studies. 
In expressing an argument that is broadly critical of (at least some) dominant conceptions of employability in university, it is important to clarify two points from the outset: first, that links between $\mathrm{HE}$ and work are not unique to the contemporary age, and second, that there is nothing inherently objectionable in such a link. The first of these is a historical question. As discussed further below, while there are some distinctive elements of contemporary understandings and manifestations of employability, it is clear that at no point in history was the university completely divorced from the realities of political economy, nor from the requirements of preparing individuals for work. The second is a normative question. This article is not presenting a view of HE -- or of education as a whole -- that sees practical application as a 'sullying' of pure academic enquiry, or that sides exclusively with 'liberal' as opposed to 'vocational' education. The point is not that universities should focus their efforts away from work, but that attention is needed to the nature of the preparation for work that universities provide, and its relationship with the institution's broader aims.

\section{What is employability?}

While employability is often gauged through employment, the two concepts are clearly distinct. Employability is a quality of the individual facilitating the gaining of employment, but is not a guarantee of it: there are many external factors that will determine whether an individual actually acquires employment, including the general availability of jobs, the distribution of different types of job, potential discrimination in the job market, and a range of other facilitators or constraints (McGrath 2009; Morley 2001). Yorke's (2004) often cited definition expresses these different elements of the core concept:

a set of achievements - skills, understandings and personal attributes - that makes graduates more likely to gain employment and be successful in their chosen occupations, which benefits themselves, the workforce, the community and the economy.

There is a large body of literature discussing the kinds of employability qualities that universities should be promoting (e.g. Hager \& Holland 2006; Harvey 2000; Pegg et al. 2012; Yorke \& Knight 2006). Various forms of skill set have been promoted - 'transferable' skills, 'core' skills, 'key' skills - while variants of these sets of generic qualities have manifested themselves in the specification of 'graduate attributes' by particular universities (e.g. the University of Melbourne ${ }^{2}$ ) and in the concept of graduateness (Steur et al. 2012) -- both of which include employability, but also other attributes of a successful life. Critiques of the skills agenda, questioning not only its narrowness, but also the very possibility of transferability of skills from one domain to another (see Bridges 1993) have led to alternative approaches. Holmes (2001; 2013), followed by others such as Hinchcliffe and Jolly (2011), have proposed a 'graduate identity' approach, which acknowledges the relational nature of these attributes, as opposed to the purported "unobservable 'tool-like' entities within the graduate" (Holmes 2001: 113).

\footnotetext{
${ }^{2}$ The University of Melbourne (2014) graduate attributes are as follows: academic distinction, active citizenship and integrity and self-awareness.
} 


\section{Should anybody be promoting employability?}

Employability is closely bound up with the recent developments in capitalist societies loosely designated by the term 'neoliberalism'. By way of a brief précis: since the 1970s, nations (particularly high income ones) have moved from welfare systems underpinned by Keynesian economics and a strong interventionist state, increasingly towards 'neoliberal' ideas of freemarket systems, with the state reframed as regulator rather than provider, and public services provided through quasi-markets with considerable private involvement. As part of this trajectory, workers face increasing uncertainty, commonly have portfolio careers rather than jobs for life, and instead of the state, are themselves held responsible for their own employment outcomes, which can be improved through developing their own human capital (Allais 2014; Brown, Lauder \& Ashton 2011). Employability, therefore, becomes the obligation of individuals in the contemporary economic landscape to ensure their own employment, income and survival. Individuals must equip themselves with the attributes necessary to respond to a rapidly changing employment market to allow themselves to maintain work and transfer between jobs.

While debates about the link between the knowledge and skills of graduates and their employment are not unique to the contemporary era, there are distinctive features of the current conceptions of employability in relation to the university. First, contemporary conceptions of employability are distinctive in their generic nature: that there is a range of attributes that can aid graduates in the gaining and maintaining of a wide range of different forms of employment, rather than a specific profession or trade. Second, the rise of conceptions of the knowledge economy have meant that higher-order analytical skills are perceived to be at a premium, thereby placing a value on higher education for increasing proportions of the population. Third, there is a change of scale and intensity, with concerns about employability and employment influencing almost all aspects of university life and profoundly changing students' and academics' conceptions of the purposes of higher education.

The process of individualisation of responsibility for employment outlined above can be interpreted as an abrogation of responsibility on the part of the state. Instead of ensuring opportunities and welfare for all, the state is -- in the name of fostering efficiency and economic competitiveness -- allowing the wealthy to maintain their privileges, and passing responsibility for disadvantage to the disadvantaged themselves. According to this view, employability is a sleight of hand, convincing people that their own employment success or failure does and should rest in their own hands, and thereby legitimising inequalities. (See again the slippage between 'employability' and 'employment' - converting the former into the latter depends on a range of macro-economic factors that are far beyond the reach of the individual).

Endorsing the discourse of employability, therefore, would appear to be endorsing the capitalist economic system. It is clearly beyond the scope of this article to present a definitive argument against this form of economic system, or alternatively to defend it. Suffice it to say that the system as currently arranged -- even with the considerable checks and softenings provided by the vestiges of the welfare state -- leaves many without the opportunity to pursue 
flourishing lives. Nevertheless, following Swift (2003), we need to reason both about what the "rules" of the game should be, and about what to do given the current rules. For the time being at least, we are faced with liberal capitalist systems, and there is moral reasoning to be undertaken in relation to the current context, as well as about how to change that underlying system potentially in the future. To put it simply, if it is the case that currently individuals require enhancement of their employability in order to gain and maintain employment, and employment is essential to survival and flourishing, then those in a position of being able to influence that employability should do so. Unavoidably, this course of action presents the potential danger of reinforcing an unjust system through playing within the rules (and consequently this argument may be rejected by those with a utopian bent).

There are clear individual benefits to employability - primarily, increasing one's chances of gaining an income - but there may also be collective benefits, perhaps for the whole of society. Some of the qualities associated with employability -- such as critical thinking, problem solving, communication skills etc -- will make graduates more productive workers, and will increase the productivity of the company or other workplace, and increase aggregate economic activity. (This logic underpins classical human capital theory [e.g. Schultz 1961], in seeing a link between investment in education and individual productivity, and thereby earnings and macro-economic growth). Enhanced worker effectiveness may also bring noneconomic benefits to others in society, say in the case of local council officials providing a better quality service to communities, or environmental scientists contributing to more extensive protection of wildlife areas.

In summary, employability is part and parcel of the highly problematic contemporary capitalist economic system. To support it may entail a reinforcement of that system. Nevertheless, in the current context, leaving individuals 'without' employability would considerably diminish their life chances, and therefore there are moral obligations to support others' pursuit of it. In addition, attributes of employability can enhance an individual's productivity in the workplace and thereby provide benefits for society.

However, any promotion of employability needs to be qualified in relation to two provisos: those of a potential zero-sum game, and ethical considerations.

\section{Zero-sum game employability}

Part of what comes under the umbrella of employability initiatives are forms of support for students designed to help them in the process of obtaining a job, i.e. finding out information about employers, filling in application forms and writing CVs, presenting oneself appropriately, performing well in interview and so forth. Most importantly of all, students can be facilitated in making contact with employers, developing their social networks, increasing their familiarity with companies and individuals. Empirical research (e.g. Mason et al. 2006) has shown the importance of work placements and 'sandwich' training placements for gaining employment subsequently, not only in terms of the skills gained but also through the contacts developed. 
These are qualities that enable an individual to obtain a job instead of somebody else. They do not relate to improvements in the productivity of the individual, and while the determination and initiative required in the competition for scarce employment opportunities might be seen to be a proxy for the qualities needed within employment, the kinds of the job application tips normally gained do not necessarily help the individual in her subsequent work. Hence, they amount to a zero-sum game: in the context of scarce opportunities, they enable those who are lucky enough to have had that exposure to employability enhancement to gain advantage over others.

Zero-sum game employability is clearly of interest to the individuals involved, but does not bring an aggregate benefit to society. In addition, as discussed below, it raises questions of equity as regards those who do and do not have access to this kind of careers advice input. (Indeed, there may be an argument instead for targeted provision in this area specifically to equalise the chances of disadvantaged groups.) Employability initiatives that provide individuals with positional advantage, therefore, but without enhancing their productivity, have a weaker justification. They can be defended on the basis of the interests of individual students, but not on the basis of those of society as a whole.

\section{Unethical employability}

Another area of concern is around unethical or 'company first' practices in employment. In a competitive market-based economic system, corporations as well as individuals compete with one another, and if we endorse the logic of capitalism, that competition in the aggregate will make a society more productive and more efficient. However, it is undeniable that those forms of competition also breed deception (both between companies, and of consumers -through misleading advertising etc), exploitation of workers, harmful impacts on local communities and environmental destruction, to name a few. Certain qualities associated with employability may enhance individuals' capacity to obtain and maintain employment, but also allow or even encourage them to contribute to practices that will be harmful to others. Capacities for problem solving, communication, and so forth can just as easily be attributes of a psychopath as of a saint. Employability, therefore, needs to be promoted within the bounds of ethical action: the way one acts within employment should be guided not only by the interests of one's direct employer, and one's own interests, but also the interests of others in society.

\section{The role of universities}

There are, therefore, concerns about the promotion of employability generally speaking, and at the very least certain caveats in doing so. Yet even if we could provide a full endorsement of employability, it would still not necessarily follow that universities should be tasked with promoting it. Consideration of the role of universities in employability must start from a discussion of their broader purpose. In light of the dramatic changes facing the institution, the question, "What are universities for?" has been posed by a number of commentators in recent years, including public intellectuals such as Umberto Eco (2013) and Boaventura de Sousa Santos (2004). In particular, the question has been eloquently addressed by Stefan 
Collini (2012) in his book of that name, and this article broadly endorses the position presented there. Nevertheless, some further discussion of the nature of the university as institution and its possible purposes will be of use.

While institutions of higher learning have emerged in different forms around the world through history, the contemporary institution of university has its roots in the establishment of guilds of students and teachers in mediaeval Europe, first in Bologna and Paris in the 12th century (Perkin 2007; Carpentier forthcoming). The early universities combined a broad grounding in the key knowledge areas of the trivium (grammar, rhetoric and dialectic) and the quadrivium (music, arithmetic, geometry and astronomy), with a subsequent and more specific formation in theology, law or medicine. While facing a range of challenges in their relations with their host cities, and with the competing powers of Church and state, they expanded in number and size through the following centuries until a decline in the $1700 \mathrm{~s}$, as they became increasingly out of touch with the social and scientific developments of the Enlightenment. Revival of the institution in the 19th century (in part due to the Humboldt's model of the research university developed in Berlin in 1810), was accompanied by a significant change in its orientation and functioning, moving away from Aristotelian argumentation and towards scientific discovery and the incorporation of new forms of work emerging in the Industrial Revolution, particularly engineering. Links with industry intensified through the 20th century, along with a dramatic expansion of participation, leading again to a broadening of the institution's purpose in relation to diverse areas of study (now incorporating teaching, nursing and social work), and an array of different service functions for society (Kerr 1963). In the early 21st century we are viewing an institution under intense pressure both to further expand and to commercialise itself, facing either the prospect of becoming a vibrant knowledge hub, or alternatively the quasi apocalyptic vision of 'unbundling' (Barber et al. 2013; Clark 1998; Wissema 2009).

The purposes of the university have, therefore, transited between transmitting a body of knowledge for the core professions, fostering scientific enquiry for furthering the interests of the nation-state, serving diverse societal interests -- community, industry, government -- and driving economic growth through human capital formation and technological innovation. Given this diversity of purposes and functions, we cannot, therefore, read off from history what the aims of a university should be, as if by digging down through the layers and discovering the true and original essence. Aviram (1992) also alerts us to the dangers of identifying the core meaning of higher education through conceptual analysis. Nevertheless, we can point to some features that are common to manifestations of the university. First like schools - they are institutions of teaching. Second - unlike schools - they are locations for the production, discovery or development of knowledge. True, in the medieval university, 'research' was not a feature, but the institutions were nevertheless sites of scholarship and development of interpretations of existing knowledge.

Collini frames this central characteristic as follows: "the governing purpose [of universities] involves extending human understanding through open-ended enquiry" (p.92). We could of course provide more detail to the definition, but much of that extra detail would end up in context specificity, or smuggling in of normative views. In the above statement we have an expression of both the overarching aim (human understanding) and the primary means 
(open-ended enquiry), although the latter can also be understood as an end in itself. 'Understanding' as a purpose contains within it both the teaching and research elements: teaching and learning as the process of encouraging understanding in students, and research or scholarship as a process of furthering the understanding of the researcher and of humanity. Universities undoubtedly have other more specific functions and purposes, but as this element appears broadly connected to the idea of a university, I will take this as its base purpose.

In observing the changing nature of the university across time -- and indeed in relation to place -- it can be seen that differences manifest themselves in relation to various dimensions of the institution's relationship with knowledge, enquiry and understanding. First, in terms of the value that is given to knowledge: whether it is seen to have intrinsic worth, or alternatively instrumental worth, and which kinds of instrumental value it might have. A second area relates to the function of the university in relation to knowledge, whether it is engaged in transmission, production or application, or a combination of the three. A third question relates to the degree of porosity of the institution, in terms of both inward and outward movement: the absorption of the ideas, individuals and purposes from outside of the university, as well as sharing the fruits of scholarship with the broader society. While all of these questions have some relevance for employability, for the purposes of this article I will focus primarily on the first of these, relating to intrinsic and instrumental value.

\section{Intrinsic and instrumental worth}

Employability is customarily seen as an instrumental benefit of higher education, in that it is external to the value of knowledge and understanding themselves - and associated processes of enquiry, dialogue and debate. (Instrumental or extrinsic is here taken to mean that the value of an activity resides outside itself, whereas intrinsic indicates that it has reached its 'resting place' and as a source of value in itself). So should we discount it as an aim of universities on that basis?

By far the best-known expression of the intrinsic value of university education - indeed possibly the best-known work on the university of all time - is Cardinal Newman's The Idea of a University Defined and Illustrated (1852). In this work, in which he defends a model of liberal education in the establishment of a new Catholic university in Dublin, he asserts that:

I am asked what is the end of University Education, and of the Liberal or Philosophical Knowledge which I conceive it to impart: I answer, that what I have already said has been sufficient to show that it has a very tangible, real, and sufficient end, though the end cannot be divided from that knowledge itself. Knowledge is capable of being its own end. Such is the constitution of the human mind, that any kind of knowledge, if it be really such, is its own reward. (p.128)

Collini's (2012) work -- while certainly sympathetic to Newman's concerns about excessive instrumentalisation -- is in fact critical of the classic text. The two authors concur that universities cannot make a person morally good - in Newman's conception, a good Catholic. 
But Newman's claim that university study will indeed make people into the ideal of a fully balanced, enlightened gentleman seems somewhat far-fetched for the contemporary writer. For Collini, it is not clear why only university can fulfil this function, and whether a three-year stint as an undergraduate can actually have such a transformative effect.

The point pertinent to our discussion here is that Collini recasts Newman's 'hardline' opposition to any instrumental benefit. Instead, Collini presents a more nuanced view:

It is sometimes said that in universities and colleges knowledge is pursued 'for its own sake', but that may mis-describe the variety of purposes for which different kinds of understanding may be sought. A better way to characterise the intellectual life of universities may be to say that the drive towards understanding can never accept an arbitrary stopping-point, and critique may always in principle reveal that any currently accepted stoppingpoint is ultimately arbitrary. (p.55)

It is not, then, that the kinds of enquiry undertaken in universities can and should have no instrumental benefit, but that if they are tied to specific, predefined forms of instrumental benefit (either in their motivations, or in the parameters of their outcomes) then that enquiry is undermined and impoverished. A further point made -- and one backed up through many examples of scientific research through history -- is that it is hard to determine at a particular point in time which knowledge is in fact useful, or will become so in the future. These central points will be pursued further below.

In his commentary on The Idea of a University, Dunne (2006) also makes a refinement of Newman's defence of the intrinsic, noting that, "Newman is surely right to oppose utility as the criterion of knowledge. But is he not mistaken, in turn, to make non-utility its criterion?" (p.424). Drawing on Alisair Maclntyre, Dunne argues for an enlarging of "the domain of the non-instrumental", by acknowledging the internal goods of apparently instrumental practices - such as medicine or architecture - involving:

competencies proper to each practice - technical proficiencies in, for example, draughtsmanship or diagnosis - and virtues of character - for example, patience, temperance, courage or honesty - that discipline one's desires and direct one's energy and attention so as to serve the demands of particular practices. (p.426)

These reflections on the kinds of intrinsic value that may pertain to professional practices, in addition to knowledge, are significant for discussions of employability. As will be discussed further below, promotion of employability is commonly focused on the 'external rewards' rather than the intrinsically valuable practice of work contained to in Dunne's conception.

In relation to the intrinsic or instrumental benefits of higher education, there are three principal positions that can be taken: 
1. Higher education ${ }^{3}$ should only have intrinsic value

2. Higher education can (additionally) have instrumental value, but only some instrumental aims are valid

3. Higher education can foster any instrumental aim held by individuals or society

The first position is hard to sustain. It is entirely legitimate for learners, their teachers (and others concerned with their education) to have instrumental aims for their learning -- in the sense of other opportunities for 'doing' and 'being' (in Sen's [1992] terms) that are opened up by it. In addition, even learning motivated by intrinsic value will often have instrumental benefit as a kind of 'accidental' positive externality. What should certainly be guarded against is a framing of higher education as only having instrumental benefit -- i.e. a view of the arts and humanities as only having value in so far as they drive a country's media industry. Instrumental aims are then valid in addition to intrinsic aims. Yet as indicated by Collini above, we should not conceive of the instrumental value as entirely external to the intrinsic value: the kinds of enquiry engaged in by universities will 'naturally' lead to useful outcomes -though not in all cases, and not in predictable ways.

A rejection of the purely intrinsic view (1) does not necessarily lead us on to position 3 , that any aim is consequently legitimate. The market-based conception of higher education -- with which the employability agenda is tightly bound -- assumes that universities should answer to the demands of consumers (as discussed in Martin, forthcoming): whether in providing the types of taught courses requested by students, the types of research requested by corporations, and other forms of knowledge exchange requested by other groups in society. While it is undoubtedly desirable for universities to be responsive to society, there are limits to the demands that can and should be answered.

We can discriminate between aims on the basis of either their moral and political value, or on their consistency with the fundamental purpose of the university, i.e. to develop human understanding. There is not space here to provide a full account of the ethical dimension of the university. Nevertheless, this article takes as a fundamental presupposition that all teaching and learning (and research) have moral and political implications, whether or not they are dealing explicitly with moral and political affairs. For sure, values are already strongly formed by the time most students are within higher education, and their time within university is limited -- hence Newman's and Collini's concerns about the potential of universities to form 'good' people. All the same, universities can have at least some influence (see Trow 1976) - positive or negative - on individuals' ethical development, through the formal taught components, the broader 'campus' environment and the nature of relationships formed within the university community. This emphasis on the development of character has been particularly strong in some contexts -- for example the elite universities in England, and the liberal arts colleges in the USA (Perkin 2007) -- but, in more subtle forms, is an inescapable aspect of higher education. Contemporary work on the ways universities can promote (or not) commitment to social justice in graduates can be seen, for example in Walker et al.'s (2009) analysis of the development of 'pro-poor professionals'. As in Walker's work, this article is underpinned by a conception of ethics expressed through Sen's (1992) dual notions of agency and well-being, and hence by the university's role in promoting these

\footnotetext{
${ }^{3}$ This article is addressing the teaching function of universities primarily, but similar arguments could apply to research.
} 
freedoms and achievements in individual students, as well as fostering in students a commitment to ensuring the agency and well-being of others.

In terms of the second consideration (consistency with the fundamental purpose of the university), the instrumental aims of universities should be fruits of the development of human understanding, or constitutive of that development - in the latter case that the process of developing understanding continues through the subsequent activity. So, for example, it is legitimate for a university to hold the aim of forming graduates equipped to function in the area of hospitality and tourism management, as long as the process of formation is underpinned by enquiry (for example, into the complex positive and negative effects of opening up a previously isolated region to tourism), and the open enquiry engaged in and understanding gained continues into and informs the subsequent work.

Universities have intrinsic worth, then, but instrumental value should not be rejected, as long as it is consistent with ethical principles and the fundamental purpose of furthering human understanding, and as long as it emerges as an outgrowth of the intrinsically valuable enquiry engaged in.

There are two important aspects of this question that this article will not be able to cover fully. As discussed above, the first relates to ethical dimension of discriminating between aims (either of teaching and research) that could be considered morally desirable or not. The second relates to equality of opportunity. One aspect of the benefits conferred by universities addressed by neither Newman nor Collini is positional advantage. (In fact, Collini's account says little about equity and equality at all, manifested in higher education principally through the question of access). In addition to intrinsic and instrumental value, education can be seen to confer positional benefits, that is to say benefits for the individual relative to others in society (Unterhalter \& Brighouse 2007). We can classify this form of benefit as a species of instrumental value, one relating to scarce and rivalrous goods, such as high-value employment opportunities. Higher education is particularly influential in relation to positional goods, and historically has acted as a key mechanism for maintenance and sometimes intensification of elite privilege in relation to wealth and political power.

Employability provision across a higher education system (and possibly within a single university as well) could be rejected on the basis that it unfairly prejudices some social groups and individuals in relation to others. Sociological research (see Tomlinson 2012) has shown that employability initiatives currently adopted by universities favour middle-class students. The nature of the employability provision, as well as its distribution, would then be relevant in terms of whether universities have a mitigating or exacerbating effect on socio-economic inequalities. The dangers here are particularly acute in the context of scarce employment opportunities alluded to in the discussion on zero-sum game employability above. 


\section{Can universities promote employability? And are they better placed to do so than other institutions?}

It is then at least permissible for universities to promote some variants of employability as part of their instrumental aims. But is it in fact possible for them to do so, and indeed efficient in terms of the range of alternative social organisations that might fulfil the function? These questions are primarily empirical, but some brief considerations will be of use.

If we consider the list of generic attributes associated with employability -- written and oral communication, critical thinking, team working, problem solving and so forth -- we can see that none of these are exclusively the domain of higher education. All of these qualities can and should be developed during school, and indeed in other spheres of life. That is not to say that some at least of them cannot also be developed in university, but it is quite wrong to attribute any failings in these areas necessarily with a failing of the university. Unfortunately, the simple fact that university comes chronologically before the primary phase of full-time employment leads people to the belief that it is the major or even the only influence on employability.

Equally, there is no reason to believe that university can have no influence on these qualities. Values are developed from early childhood, and it may be that major changes are unlikely after reaching adulthood, but -- as discussed above -- even in this area some development is possible. The areas that university can contribute to most strongly would appear to be qualities such as: disciplinary knowledge through degree courses, useful for employability most obviously in professional courses such as engineering, architecture etc; development of critical thinking; analytical skills and interpretation of texts; higher-level written communication; development of values associated with research and scholarship, what we might call the 'spirit of enquiry'; and the experience of living and working with diverse others.

Nevertheless, there are aspects of employability that universities cannot meaningfully contribute to. For most lines of work, job specific skills -- and knowledge of an applied, practical rather than a general, theoretical nature -- can best, or perhaps can only be learned from the employer, and in the workplace. As Mason et al. (2006: 26) state, "There may be little to be gained from universities seeking to develop skills that are best acquired (or can only be acquired) after starting employment rather than beforehand". Some personal and work qualities - such as teamwork, responding effectively under pressure - may be enhanced by simulations in the university but are best acquired through experiential learning. Universities, therefore, can develop part of what is included in lists of employability attributes, but much is best developed within the workplace -- and in that category can be included the forms of work placements that are provided during a degree course, but are not conducted within the university itself (such as an attachment at the headquarters of a national hotel chain for students of Tourism). We might, in this regard, propose that degree courses should be more porous and facilitate these forms of experiential learning beyond the university gates to a greater extent. In addition, there are a variety of post-secondary institutions of a vocational nature that may be better equipped at enhancing employability in particular areas. These considerations are important as they guard against overreach in relation to the potential of universities for promoting employability, as well as unfounded expectations about the kinds of attributes that universities can develop. 


\section{Are there any costs?}

Even if it can be shown that promoting employability is consistent with the purpose of the university, and that it is possible for universities to do so, there may still be arguments against it if it can be shown that there are associated costs. Promoting employability might, in this way, detract from other activities undertaken by universities. There are two ways in which such a negative effect might occur -- relating to 'quantity' and 'quality', in a manner of speaking. In the first, allocation of time and resources to fostering learning related to employability would leave less time for other activities: a compulsory module on 'entrepreneurial skills', for example, would mean one fewer modules on medieval Italian poetry or quantum physics; resources spent on expanded careers services would mean a smaller fund for library collections in demography and social work. This kind of trade-off would be avoided if the activities in question were 'dove-tailed', though such a fusion would not be possible in all cases.

A second more elusive, and potentially more dangerous, prospect is that the incorporation of employability might undermine the university's other functions in a qualitative sense. According to this argument, orientation of course content to the needs of current employers might encourage a change in relationship to knowledge among students (and possibly academic staff), towards a valuing of learning only in so far as it can provide an immediate, tangible and most probably economic benefit. Furthermore, the applied and concrete may come to squeeze out the theoretical and abstract, in order to attend to the perceived needs of employers. This process would parallel the movement brought about through contemporary research funding arrangements from basic or 'blue skies' research to applied research (often with intellectual property controlled by the funding corporation).

As discussed extensively by Collini, one of the primary characteristics of the activities of universities is that they are "open-ended". The kinds of teaching and research activities undertaken there are characterised by unpredictability, and indeed the impossibility of predefining the outcomes of either in any exact sense is the source of their value. As Collini states: "Intellectual enquiry is in itself ungovernable: there is no predicting where thought and analysis may lead when allowed to play freely over almost any topic" (p.55). A research study may take an unexpected course, and in deviating from its original purpose may make a discovery considerably more valuable than that intended. Students may leave university having developed in a personal, civic and professional sense in ways entirely unexpected but nonetheless significant. It is not only that defining too closely the outcomes of these processes is unlikely to succeed, but that such a predefinition can impoverish the process and rob it of its generative potential (McCowan 2013).

Employability activities undertaken by universities would therefore need to guard against such potential negative impacts, and external bodies concerned with the employability promoting potential of universities would have to accept the unpredictability of the process. A business studies student may well emerge from university with substantial concerns about the impact of multinational corporations on low-income countries and the natural environment: such a perspective would prove problematic in a workplace in which 
compliance and subordination of beliefs to the prosperity of the company were required. While there may be occasions in all forms of work in which personal beliefs may be subordinated to the objectives of one's employer or profession, the capacity for critical reflection on one's work and for action in accordance with it, are essential attributes of a graduate.

\section{Final thoughts}

While universities may be valued primarily for their intrinsic benefits, it is neither possible nor desirable to avoid additional instrumental benefits. However, acceptance of this point does not lead us inevitably to a consumer model in which universities simply respond to whatever aims are brought to their door by individuals and society (akin to factories adapting their machinery to respond to the changing demands for industrial products). Judgements can be made on the desirability or coherence of different potential purposes of the university on the basis of moral and political considerations, as well as those of furthering human understanding.

Employability, therefore, should be subjected to this form of discernment. It can potentially be justified both on the basis of individual and collective interests: in relation to the former, the need for individuals to gain employment as a means of survival and sustenance, and the role of meaningful work in human flourishing; in relation to the latter, the enhancement of productivity and professional capacity that will benefit the whole of society. However, it is hard to justify the promotion of employability attributes that lead merely to positional advantage, or to prejudicial effects on others. Importantly, there is a danger that the employability agenda will exacerbate the recent trends towards conceptualising higher education primarily in terms of private goods; both the 'public goods' and the 'public good' dimensions of higher education need to be fully acknowledged (Marginson 2011).

Furthermore, the employability 'agenda' should not be promoted to the extent that it undermines the core function of university in fostering understanding. As argued above, the instrumental value of universities should exist alongside and emerging from its intrinsic value, rather than replacing it. Moreover, following Dewey (1964) and Oakeshott (1989), the conventional view of aims-oriented activity (in this case, employability goals determining the functionings of a university) can be seen as something of an illusion: a range of instrumental benefits including employability may emerge from the university's work, but it is not the former that brings the latter into being. "The university is not a machine for achieving a particular purpose or producing a particular result; it is a manner of human activity" (Oakeshott 1989: 96).

It is important to re-emphasise that this article is not arguing against connections with the world of work or professional development in universities. Work is a fundamental part of human life and a significant source of value, and universities should (as they have through the centuries) form graduates who are equipped to function in specialised areas of employment. Peters (1981), in relation to this point, makes a distinction between 'work' and 'labour' (drawing on Hannah Arendt), the former involving meaningful work involving skill leading to a rewarding end-product, and the latter characterised by Marx's 'alienation', involving little 
skill, fostering little responsibility, with rewards that are entirely extrinsic. For Peters, while education should not prepare for 'labour' at all, there is justification for work as an aim, as long as it is not just "narrow training", and serves "as a way into the understanding of principles of a more general application and a focus for more general matters of human concern"(p. 48). Understandings of the kinds of professional preparation that might be justified in universities are also aided by Winch's (2006) distinction referred to above between the development of technological rather than merely technical knowledge, enabling graduates to reflect critically on and shape their work environment, involving not just the ability to apply theoretical knowledge for a particular purpose, but "the capacity to contribute to the theoretical component of that applicable knowledge" (p.68). Our focus then should not be on whether universities should prepare their students for work, but on the ways in which they do so.

But what if the question were posed of whether universities should be obliged to promote goals outside their core remit (fostering human understanding) if there were sufficient societal interest? Why should universities stick to doing what they do best if there are other pressing demands? For sure, in an extreme situation such as a food crisis, universities should willingly turn over their grounds and human resources for agricultural production on a temporary basis. However, the same argument does not apply to more general societal demands, for two reasons. First, in terms of efficiency, there may well be other institutions better equipped to do so: and, as discussed above, in the case of employability, many of the proposed attributes are in fact more effectively or efficiently developed within the workplace or more specialised forms of vocational training. Second, (and while there is not the space here to cover the empirical evidence in full), the contribution of universities to societal development and individual well-being in the long run is substantial - even if the exact nature of the contribution is difficult to predict.

An important final question concerns whether the considerations for private universities might be different from public universities in relation to these discussions. Very few institutions around the world are now in fact 'purely' public - in the sense of being both funded through tax revenue and established or controlled by the state (as in the case of the Brazilian and Argentinian state universities, for example). Most universities have some private involvement (either in funding or provision), even if they are not fully private or for-profit. It is important also to recall that state involvement in higher education is to a large extent a $20^{\text {th }}$ century affair, and that the early universities were also 'private'. But are private universities, on account of their financial or management ties to specific individuals or groups, a case apart? Would they have a greater or distinct licence or obligation to promote employability?

While the lines of accountability in these cases are different, it does not appear that the above arguments would no longer apply. In the case of the central aim of furthering human understanding, for an institution that ceased to hold it as an aim, we could coherently say that it no longer fits within the category of university. So, for example, a centre which conducts research for a specific company, of an applied nature and whose findings are fed into corporate product development rather than shared with the academic community, would not normally be termed a university. The same would hold for a centre that trains employees for a specific line of work without an element of open-ended enquiry or broader intellectual development (McDonald's Hamburger University notwithstanding). In relation to 
teaching, a private university should have enquiry as its central feature just as much as a public one. In relation to the ethical dimension, while private universities may not have direct accountability to the tax-payer, they are not thereby excused all moral obligations towards society. The private nature of the relationship between the student and the university justifies promotion of unethical qualities no more than the private relationship between a client and a lawyer would justify falsification of evidence. (Of course, these discussions are at a normative level, and do not of course regiment what is happening descriptively. In practice, what students in the new consumer systems are buying is indeed positional advantage, and very often through 'zero-sum game' employability.)

Universities, therefore, should promote employability - but only a particular version of it: one consistent with - or emerging from - the aims of critical reflection and moral action. In this way, the notion of employability might seem to collapse onto what has been termed 'graduateness' - that is to say, one of the qualities of a person emerging from the experience of university is that she can gain and function effectively in employment, but that this attribute does not dominate all others, and subordinate to itself the graduate's other roles as a citizen of a polity or as a human being part of web of relationships, near and far.

\section{Acknowledgements}

I am grateful to Judith Suissa, Christopher Martin, Gabriel Goldmeier and two anonymous reviewers for their helpful comments on earlier drafts.

\section{References}

Allais, S. (2014) Selling Out Education: National Qualifications Frameworks and the neglect of knowledge, Rotterdam: Sense.

Aviram, A. (1992) The Nature of University Education Reconsidered (a response to Ronald Barnett's The Idea of Higher Education). Journal of Philosophy of Education, 26: 183200.

Barber, M., Donnelly, K., \& Rizvi, S. (2013). An avalanche is coming. Institute for Public Policy Research, London, UK. Retrieved from http://www.ippr.org/publication/55/10432/anavalanche-is-coming-higher-education-and-the-revolution-ahead

BIS - Department for Business, Innovation and Skills (2011). Supporting Graduate Employability: HEI Practice in Other Countries: BIS Research Paper Number 40. London: BIS.

Bologna Declaration (1999), The Bologna Declaration of 19 June 1999: Joint Declaration of the European Ministers of Education, European Union, Brussels, available at: 

$31 / 8 / 14$

Bridges, D., (1993) 'Transferable skills: a philosophical perspective.' Studies in Higher Education, Vol.18. No.1, pp.43-51.

British Council (2013) Graduate Employability in the Middle East and North Africa: Post-Arab Spring. Available at http://www.britishcouncil.org/employability report.pdf. Accessed 31/8/14.

Brown, P., Lauder, H., \& Ashton, D. (2011), The Global Auction. The Broken Promises of Education, Jobs, and Incomes, Oxford and New York: Oxford University Press.

Carpentier, V. (forthcoming) "The historical expansion of Higher Education in Europe: spaces, shapes and rationales", in J. L. Rury and E.H. Tamura (eds) The Oxford Handbook of The History of Education. Oxford: Oxford University Press.

CHEC (2013). Pathways from University to Work. Wynberg: Cape Higher Education Consortium.

Clark, B. R. (1998) Creating Entrepreneurial Universities: organisational pathways of transformation (New York, Elsevier).

Collini, S. (2012) What are universities for? London: Penguin.

Dearing, R. (1997) The Dearing Report. (National Committee of Enquiry into Higher Education). London: HMSO.

Dewey, J. (1964) The continuum of ends-means. In R. Archambault (Ed.) John Dewey on Education: Selected Writings. Chicago: University of Chicago Press.

Dunne, J. (2006) "Newman Now: Re-Examining the Concepts of 'Philosophical' and 'Liberal' in the Idea of a University." British Journal of Educational Studies 54(4): 412-428.

Eco, U. (2013) Perché le università? Universitas 131. Available at http://www.disf.it/files/ecoperche-universita.pdf . Accessed 2/9/14.

Hager, P. \& Holland, S. (Eds) (2006) Graduate attributes, learning and employability. Dordrecht: Springer

Harvey, L. (2000) New realities: the relationship between higher education and employment. Tertiary Education and Management, 6 (1), 3-17.

Hinchliffe, G. and Jolly, A. (2011) 'Graduate identity and employability', British Educational Research Journal 37(4): 563-584. 
Holmes, L. (2001) Reconsidering graduate employability: the 'graduate identity' approach, Quality in Higher Education, 7(2), 111-119.

Holmes, L. (2013), Realist and relational perspectives on graduate identity and employability: a response to Hinchliffe and Jolly. British Educational Research Journal, 39: 1044-1059.

Kerr, C. (1963) The Uses of the University. New York: Harper Torchbooks.

Martin, C. (forthcoming) Should Students Have to Borrow? Autonomy, Well Being and Student Debt.

Marginson, S. (2011), 'Higher Education and Public Good', Higher Education Quarterly, 65(4): 411-33.

Mason, G., Williams, G., and Cranmer, S., (2006) Employability Skills Initiatives in Higher Education: What Effects do they have on graduate labour market outcomes?, National Institute of Economic and Social Research.

McCowan, T. (2013) Education as a human right: principles for a universal entitlement to learning. London: Bloomsbury.

McGrath, S. 2009 What is employability? Learning to support employability project paper 1. School of Education, University of Nottingham. Available at: http://www.nottingham.ac.uk/shared/shared uccer/epa docs/what is employability . pdf

Morley, L. (2001) Producing new workers: quality, equality and employability in higher education. Quality in Higher Education, 7 (2), 131-138.

Newman, J. H. 1852/1947. The Idea of the university: defined and illustrated, London: Longmans, Green and Co.

Novoa, A. (2007) The 'right' education in Europe: When the obvious is not so obvious! Theory and Research in Education, 5 (2), 143-151.

Oakeshott, M. (1989) The idea of a university. In T. Fuller (Ed.) The Voice of Liberal Learning: Michael Oakeshott on Education (New Haven and London, Yale University Press), 95104.

OECD (2008a) Tertiary Education for the Knowledge Society: Volume 1: Special Features: Governance, Funding and Quality, OECD Publishing.

OECD (2008b) Tertiary Education for the Knowledge Society: Volume 2: Special Features: Equity, Innovation, Labour Market, Internationalisation, OECD Publishing

Pegg, A.,Waldock, J.; Hendy-Isaac, S. and Lawton, R. (2012) Pedagogy For Employability. York, UK: Higher Education Academy. 
Perkin, H. (2007) History of universities. In J. J. F. Forest \& P. G. Altbach (eds), International Handbook of Higher Education. Dordrecht: Springer.

Peters, R. S. (1981) Essays on Educators. London: George Allen and Unwin.

Santos, B. S. (2004) A universidade do século XXI: para uma reforma democratic e emancipatória da universidade. São Paulo: Cortez.

Schultz, T. W. (1961). 'Investment in human capital.' The American Economic Review, 51 (1): $1-17$.

Sen, A. (1992). Inequality re-examined. Oxford: Clarendon Press.

Steur, J., Jansen, E., \& Hofman, W. (2012). Graduateness: An empirical examination of the formative function of university education. Higher Education, 64(6), 861-874.

Swift, A. (2003) How Not to Be A Hypocrite: School Choice for the Morally Perplexed Parent. London: Routledge.

Tomlinson, M. (2012) Graduate employability: a review of conceptual and empirical themes. Higher Education Policy, 25, 407-431.

Trow, M. (1976) Higher Education and Moral Development American Association of University Professors Bulletin, 62 (1), 20-27.

UNESCO (2012) Graduate Employability in Asia. UNESCO: Bangkok.

University of Melbourne (2014) Melbourne Graduates. Available at http://learningandteaching.unimelb.edu.au/curriculum/graduates. Accessed 6/2/15.

Unterhalter, E. and Brighouse, H. (2007) Distribution of what for social justice in education? The case of Education for All by 2015. In M. Walker and E. Unterhalter (Eds) Amartya Sen's capability approach and social justice in education. New York: Palgrave Macmillan.

Walker, M., McLean, M., Dison, A., Peppin-Vaughan, R. (2009) South African universities and human development: Towards a theorisation and operationalisation of professional capabilities for poverty reduction. International Journal of Educational Development, 29 (6), 565-572.

Winch, C. (2006). Graduate attributes and changing conceptions of learning. In: P. Hager \& S. Holland. (Eds.). Graduate attributes, learning and employability. Dordrecht: Springer, 67-89.

Wissema, J.G. (2009) Towards the Third Generation University: Managing the University in Transition. Edward Elgar, Cheltenham. 
World Bank., (2010) Stepping Up Skills: For more Jobs and Productivity, Washington DC: World Bank.

Yorke, M. (2004) Employability in higher education: what it is - what it is not, Learning and Employability Guides (York, LTSN-ESECT), 1.

Yorke, M. and Knight, P. (2006) Embedding employability into the curriculum. York, Higher Education Academy. 